\title{
PFGE diversity within the methicillin-resistant Staphylococcus aureus clonal lineage ST398
}

\author{
Thijs Bosch ${ }^{1 *}$, Albert J de Neeling ${ }^{1 \dagger}$, Leo M Schouls ${ }^{1 \dagger}$, Kim W van der Zwaluw ${ }^{1 \dagger}$, Jan AJW Kluytmans ${ }^{2,3 \dagger}$, \\ Hajo Grundmann ${ }^{1+}$, Xander W Huijsdens ${ }^{1+}$
}

\begin{abstract}
Background: Livestock has recently been identified as a new reservoir of methicillin-resistant Staphylococcus aureus (MRSA). Most isolates belong to ST398 and are non-typeable with PFGE using Smal, making it difficult to study transmission and outbreaks. Therefore, a new PFGE using Cfr9l, a neoschizomer of Smal was optimized and evaluated to investigate ST398 isolates.

Results: After optimizing and evaluating the Cfr9I PFGE, clear and reproducible banding patterns were obtained

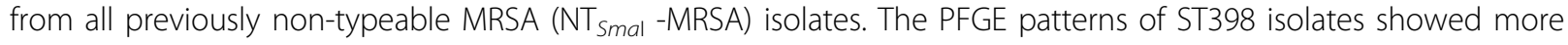
diversity than with spa-typing and/or MLST. The PFGE results showed diversity within and between the two most prevalent spa-types of $\mathrm{NT}_{\text {Smal }}-\mathrm{MRSA}$ (t011 and t108). No match was found, when comparing banding patterns of the NT Smal $-M R S A$ with 700 different PFGE types, obtained with Smal digestion, in our database of more than 4000 strains. Furthermore, possible transmission among veterinarians and their family members was investigated and an outbreak of ST398 MRSA in a residential care facility was confirmed with the Cfr9l PFGE.

Conclusions: The adjusted PFGE can be used as a method for selecting important and distinct ST398 isolates for further research. The adjustments in the PFGE protocol using Cfr9I are easy to implement to study the ST398 clonal lineage in laboratories which already have a PFGE facility.
\end{abstract}

\section{Background}

Methicillin-resistant Staphylococcus aureus (MRSA) is a major cause of nosocomial and community-associated infections worldwide. Most cases of community-associated MRSA (CA-MRSA) have been associated with skin and soft-tissue infections in previously healthy individuals [1,2]. Since 2003, pigs [3-7] and other animals such as horses $[8,9]$, poultry [10] and calves [11] have been identified as a new reservoir for CA-MRSA. Most of the livestock related MRSA strains share the same multi locus sequence typing (MLST) type, namely ST398. Throughout Europe [9,12-14], Canada [6] and in the United States [15] ST398 has been found in association with animal husbandry, indicating a worldwide clonal lineage. Although the clinical importance of ST398 is still controversial, there are reports indicating transmission and infections among humans [16-18]. Pulsed

\footnotetext{
* Correspondence: thijs.bosch@rivm.nl

+ Contributed equally

${ }^{1}$ Centre for infectious disease control, National institute for public health and the environment (RIVM), Bilthoven, the Netherlands
}

Field Gel Electrophoresis (PFGE) using SmaI is considered to be the gold standard for typing MRSA isolates [19]. When PFGE was performed on ST398 isolates, no banding patterns could be generated, due to methylation of the SmaI site [20]. Therefore, ST398 isolates are referred to as PFGE non-typeable $\left(\mathrm{NT}_{S m a \mathrm{I}}\right)$-MRSA. Some years ago staphylococcal protein A (spa) typing was introduced as a highly discriminatory typing method to characterize $S$. aureus isolates $[21,22]$. However, spatyping of the ST398 isolates revealed very limited variation within this group and $80 \%$ of our ST398 isolates had either spa-type t011, t108 or t034 [23]. Recently, a multiple-locus variable number of tandem repeat analysis (MLVA) has been presented [24]. Although MLVA is significantly more discriminatory than spa-typing, it was unable to yield a better discrimination of the isolates of the ST398 lineage. The lack of a typing method that can discriminate ST398 strains has hampered studies on the origin and transmission routes of this MRSA clade.

In the Netherlands all first MRSA isolates obtained from patients with staphylococcal disease and from 
patients that carry the pathogen are sent to the National MRSA reference centre for typing. In 2007, 30\% of all forwarded MRSA isolates were $\mathrm{NT}_{\text {SmaI }}$-MRSA [23].

Recently, a neoschizomer of SmaI, designated as Cfr9I, was shown to be insensitive for the DNA-methylation leading to $\mathrm{NT}_{S m a \mathrm{I}}-\mathrm{MRSA}$ isolates. In two studies this restriction enzyme was used for generating PFGE profiles of $\mathrm{NT}_{\text {Smal }}$-MRSA isolates $[18,25]$. In the study presented here we optimized PFGE with restriction enzyme $C f r 9 \mathrm{I}$ and evaluated its use to characterize $\mathrm{NT}_{\text {SmaI }}$ -MRSA isolates.

The data will yield important information about the genetic diversity of the ST398 clonal lineage in the Netherlands and demonstrates that Cfr9I PFGE is a powerful tool to study possible transmission and outbreaks of MRSA isolates, previously not typeable by conventional PFGE approaches.

\section{Methods}

\section{Bacterial isolates}

The National Institute for Public Health and the Environment (RIVM) serves as the Dutch National MRSA reference center. All first MRSA isolates, one per patient, are sent to the RIVM for further typing. PFGE was carried out using restriction enzyme SmaI according to the Harmony protocol [26]. From this large MRSA collection a number of $\mathrm{NT}_{S m a \mathrm{I}}$-MRSA was selected to optimize and validate the Cfr9I PFGE. To study the genetic diversity of the two most prevalent spa-types among $\mathrm{NT}_{S m a \mathrm{I}}-\mathrm{MRSA}$ in the Netherlands, $60 \mathrm{NT}_{S m a \mathrm{I}}$ -MRSA isolates $(\mathrm{t} 011(\mathrm{n}=30)$ and $\mathrm{t} 108(\mathrm{n}=30))$ in 2008 from patients living in geographical dispersed regions in the Netherlands were used. In addition, 16 strains (8 pairs) from veterinarians and one of their family members, the latter whom did not have contact with animals and 40 pig and pig farmer isolates and 6 strains from an $\mathrm{NT}_{\text {SmaI }}$-MRSA outbreak in a residential care facility [18] were included in this study to assess the potential of the Cfr9I PFGE to identify transmissions. To validate the Cfr 9 I PFGE method, 10 typeable MRSA (T-MRSA) isolates and the reference strain NCTC 8325 were tested. Five non-typeable isolates were repeated 3 times with Cfr9I PFGE to ensure the reproducibility of the method.

\section{Molecular typing}

All isolates were characterized with spa typing [22]. Spatypes were assigned using Bionumerics software version 5.1 (Applied Maths, Sint-Martens-Latem, Belgium). SCCmec typing of the isolates was performed using the multiplex PCR described by Boye et al [27].

In order to obtain clear and reproducible PFGE banding patterns using $C$ froI as restriction enzyme, the Harmony PFGE protocol had to be adjusted. This resulted in the following protocol: From each isolate, $100 \mu \mathrm{l}$ bacterial suspension of an overnight Trypton Soy Broth (TSB) culture, was embedded in a plug mold (Biorad) with $1.2 \%$ low-melting-point agarose (Seakem gold ${ }^{\circ}$, Biorad). Then, $500 \mu \mathrm{l}$ lysostaphine $(100 \mu \mathrm{g} / \mathrm{ml}$, Sigma $)$ was added and incubated for $6 \mathrm{~h}$ at $37^{\circ} \mathrm{C}$. Subsequently, the plugs were incubated overnight at $55^{\circ} \mathrm{C}$ with $500 \mu \mathrm{l}$ Proteinase K $(50 \mu \mathrm{g} / \mathrm{ml}$, Merck). The plugs were then washed, 6 to 10 times in a shaking incubator for 30 min. in $1 \times$ Tris-EDTA buffer (Fluka, pH 7) at $50^{\circ} \mathrm{C}$ in order to remove cell debris. Finally, the plugs were equilibrated in $1 \times C f r 9 I$ buffer (Fermentas, Ontario, Canada) for $15 \mathrm{~min}$. at room temperature prior to digestion and then submerged in $200 \mu \mathrm{l}$ of $1 \times C f r 9 \mathrm{I}$ reaction buffer containing $40 \mathrm{U}$ of $C$ froI restriction enzyme (Fermentas, Ontario, Canada). The reaction tubes were incubated overnight at $37^{\circ} \mathrm{C}$ in a shaking incubator. Further steps were carried out according to the Harmony protocol [26]. Briefly, a 1\% agarose gel was poured into a gel tray and positioned in a contour-clamped homogeneous electric field (CHEF) (Biorad) tank and submerged in $1,700 \mathrm{ml}$ of $0.5 \times$ Tris-Borate-EDTA (TBE). The total run time was $22 \mathrm{~h}$ at $14^{\circ} \mathrm{C}$ with an initial pulse time of $5 \mathrm{~s}$, a final pulse time of $50 \mathrm{~s}$ and a voltage of $6 \mathrm{~V} / \mathrm{cm}$ or $200 \mathrm{~V}$. Gels were stained in ethidium bromide $(1 \mu \mathrm{g} / \mathrm{ml}$, Invitrogen) and viewed and photographed with UV transillumination. Digital images were analyzed using Bionumerics software, version 5.1. If a difference in PFGE pattern was observed, a new pulsed field type was assigned. The definition of a PFGE cluster was based on a similarity cutoff of $80 \%$ [28] (Dice coefficient, represented by UPGMA, 0.5\% optimization and $1.0 \%$ tolerance). Different PFGE clusters were given in alphabetical order. Every band difference within a PFGE cluster resulted in adding a numerical order to the pulsed field cluster.

\section{Results}

Optimization and validation of the Cfr9I PFGE method

In the initial experiments the SmaI restriction enzyme was replaced by $C f r 9 I$ and exactly the same conditions were used as in the original PFGE protocol. This led to uninformative PFGE patterns consisting mainly of smears and faint bands obtained through partial digestion of the genomic DNA. A higher lysostaphine concentration $(100 \mu \mathrm{g} / \mathrm{ml})$, longer incubation steps for lysis $(6 \mathrm{~h})$, proteinase $\mathrm{K}$ and digestion overnight and hot washes at $50^{\circ} \mathrm{C}$ - instead of washes at room temperature - produced clear and reproducible banding profiles.

After optimizing the PFGE method with Cfr9I, high quality banding patterns from all selected $(\mathrm{n}=124)$ previously non-typeable ST398 MRSA isolates were obtained. For validation, both PFGE protocols (SmaI and $C f r$ I) were performed on 10 typeable MRSA 
isolates and the reference strain NCTC 8325. Side-byside comparison of SmaI and Cfr9I PFGE profiles yielded identical banding patterns consistent with unequivocal comparability of both restriction patterns. Reproducibility of the method was confirmed with 5 $\mathrm{NT}_{\text {SmaI }}$-MRSA isolates which were re-analyzed 3 times and yielded identical banding patterns.

\section{Genetic diversity of $N T_{\text {Smal }}-M R S A$}

All PFGE patterns of the $\mathrm{NT}_{\text {SmaI }}$-MRSA were compared with a database consisting of more than 4000 isolates containing over 700 different PFGE types obtained with SmaI digestion. Surprisingly, newly-obtained banding patterns of $\mathrm{NT}_{S m a \mathrm{I}}-\mathrm{MRSA}$ isolates did not match with any known PFGE cluster in the national database of MRSA isolates collected since 2002.

Thirty t011 isolates revealed 16 different PFGE patterns (figure 1). The largest PFGE cluster consisted of 5 isolates, and 5 patterns were found more than once $(\mathrm{n}=$ 19). No correlation was found between PFGE cluster and geographic location. The minimal similarity (Dice coefficient, represented by UPGMA, $0.5 \%$ optimization and $1.0 \%$ tolerance) between the different patterns was 64\% (data not shown). Thirty t108 isolates revealed 14 different PFGE patterns (figure 1). The largest cluster contained 12 isolates and 4 patterns were found more than once $(n=20)$. The clusters showed no geographical correlation. The minimal similarity of the t108 isolates was $50 \%$ (data not shown). One t108 isolate yielded a very distinct PFGE pattern (figure 1, pattern $\mathrm{H})$. Without this isolate the minimal similarity of the t108 isolates would be $80 \%$. The minimal similarity of the $60 \mathrm{NT}_{\text {SmaI }}$-MRSA isolates was $35 \%$, but most isolates share $80 \%$ or more similarity (figure 1). SCCmec typing of the $60 \mathrm{NT}_{S m a \mathrm{I}}-\mathrm{MRSA}$ isolates showed SCCmec type IV $(\mathrm{n}=14)$ and SCCmec type V $(\mathrm{n}=43)$. Three isolates yielded a variant of SCCmec type V (indicated in figure 1 with $\mathrm{V}^{*}$ ) and no SCCmec types I, II or III were found (figure 1).

\section{Transmission of ST398 isolates}

The results of Cfr9I PFGE of 8 pairs of veterinarians and one of their close family members showed that 5 pairs gave indistinguishable banding patterns suggesting possible transmission of ST398 (figure 2 shows 2 pairs of indistinguishable banding patterns). Two pairs that did not match also had different spa-types (figure 2). One pair which had the same spa-type differed in a single PFGE band (data not shown). Six isolates belonging to an outbreak in a residential care facility with spa-types t2383 and t011 all shared the same banding pattern (figure 2). Furthermore, the transmission between pigs, pig farmers and their family on 9 different pig farms (table 1, figure 2) was studied. Farms 1 to 5 shared the same spa-type whereas on farms 6 to 9 , two or more different spa-types were present. The number of different PFGE patterns (B1-K) differed between farms, ranging from indistinguishable patterns (farm 4) to 5 different PFGE patterns (farm 8). PFGE patterns B1, D1, D3, D4 and E1 were found on several farms (table 1). The minimal similarity within the farms varied from $52 \%$ (farm 5) to $100 \%$ (farm 4) and the minimal similarity between the farms was $61 \%$ (data not shown). Figure 2 shows the PFGE results of farm 6 with 4 different PFGE patterns and from farm 9 which all had indistinguishable PFGE patterns.

\section{Discussion}

MRSA isolates belonging to the ST398 clonal lineage are hard to discriminate based on spa-typing and/or MLST, hampering the assessment of transmission and outbreaks. Therefore, other techniques such as a modified PFGE could provide a new opportunity to differentiate ST398 isolates. The restriction enzyme SmaI does not cut the DNA of $\mathrm{NT}_{\text {SmaI }}-\mathrm{MRSA}$ isolates, due to methylation of the SmaI site. However, Cfr9I, a neoschizomer of SmaI, can be used for generating PFGE profiles of the $\mathrm{NT}_{\text {SmaI }}$-MRSA isolates. When the standard SmaI protocol was used for $C f r$ II, banding patterns with smears and partial digests appeared. Other recently published articles seemed to have encountered similar problems with their $C f r 9$ I PFGE $[18,25]$. The results indicated that lysis of ST398 isolates and digestion with restriction enzyme $C$ friI is more cumbersome than lysis of typeable MRSA and digestion with SmaI [29]. After modifying the protocol, banding patterns of similar quality as those of typeable MRSA isolates digested with SmaI were obtained. All previously non-typeable MRSA isolates can be typed with the optimized PFGE method providing a new opportunity to differentiate the ST398 clonal lineage.

From April 2002 until January 2008, all MRSA isolates sent to the RIVM have been typed with PFGE using SmaI as restriction enzyme creating a database with more than 4000 isolates with over 700 different PFGE types. Since $C f r 9 I$ recognizes the same restriction site as SmaI, Cfr9I enables analysis and comparison of the patterns with other profiles in our database. No comparison was found when comparing banding patterns of $\mathrm{NT}_{\text {SmaI }}$ -MRSA with known PFGE patterns, suggesting that $S m a I$ restriction modification is confined to a defined clonal lineage. Recently, ST398 isolates were typed using amplified fragment length polymorphism (AFLP). These data also suggested that ST398 is a distinct cluster recently introduced into the Dutch patient population [30].

The PFGE patterns of the two most prevalent spa-types (t011 and $\mathrm{t} 108$ ) within the $\mathrm{NT}_{\text {SmaI }}$-MRSA isolates showed more variation than spa-typing or MLST. The genetic diversity within the ST398 clonal lineage of MRSA sharing 


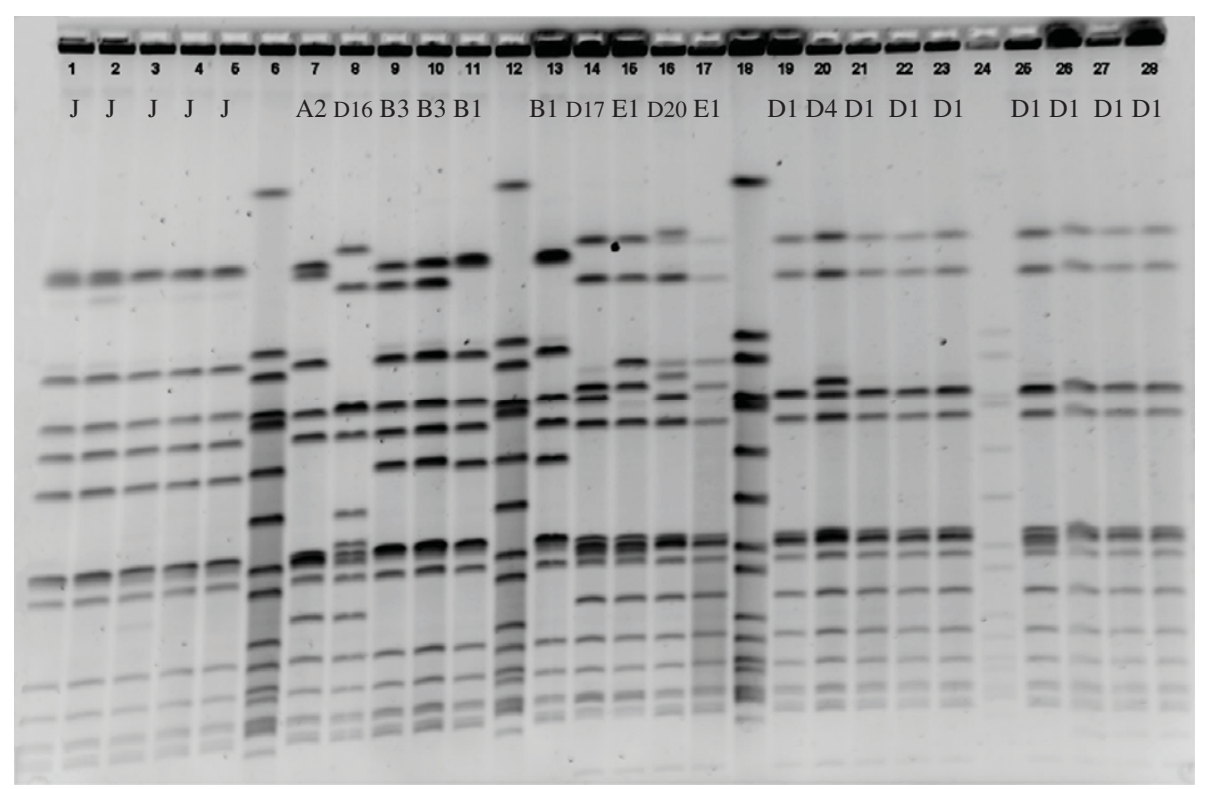

Figure 2 PFGE patterns of ST398 isolates digested with Cfr9l restriction enzyme using NCTC 8325 as the reference standard. Lanes 6, 12, 18, and 24, NCTC 8325; Lanes 1-5, isolates from an outbreak in a residential care facility, all PFGE pattern J; Lanes 7-8, and 14-15, two pairs of a veterinarian and a close family member with distinct PFGE patterns; Lanes 9-11, and 13, two pairs of a veterinarian and a close family member with identical banding patterns; Lanes 16-17, and 19-22, isolates of pig farm 6 with four different PFGE patterns; Lanes 23, and 25-28, isolates

from pig farm 9 with identical banding patterns

the same spa-type creates an opportunity for improved investigation of outbreak and potential transmission events. Spa-typing, which is currently used as a MRSA typing standard, cannot differentiate these isolates further. Using Cfr9I PFGE, spa-type t011 seemed to be more diverse than t108. Although the minimal similarity of the t108 isolates was $50 \%$, this was mainly caused by a single isolate with a very distinct PFGE pattern (pattern H). Without this isolate the minimal similarity of the t108 isolates was $80 \%$. The t011 isolates showed a minimal similarity of $64 \%$ (data not shown). SCCmec typing showed an almost equal distribution between SCCmec type IV ( $\mathrm{n}=$ 14) and $\mathrm{V}(\mathrm{n}=16)$ for t011 isolates, whereas all t108 isolates carried SCCmec type V or a SCCmec type V variant. Huijsdens and colleagues performed SCCmec typing on $300 \mathrm{NT}_{\text {SmaI }}$-MRSA isolates and they showed similar results [23]. This variation in SCCmec types may also indicates a higher diversity among t011 MRSA isolates compared to t108 isolates.

The minimal similarity of the Cfr9I PFGE patterns among ST398 isolates was 35\% and showed variation within spa-types, but the diversity within this lineage is still limited. Furthermore, one isolate with spa-type t108 yielded a very distinct PFGE pattern which causes the similarity to be $35 \%$ (figure 1). When excluding this isolate from the dendrogram the minimal similarity was $62 \%$. Comparing the PFGE results using the criteria by Tenover et al. and when a similarity cut-off of $80 \%$ was applied, most $\mathrm{NT}_{S m a \mathrm{I}}-\mathrm{MRSA}$ isolates should be classified as one PFGE cluster [31,32]. However, the Cfr 9 I PFGE is still better in discriminating possible differences between $\mathrm{NT}_{\text {SmaI }}$-MRSA isolates.

No geographical relation could be found in either spatype. However, most $\mathrm{NT}_{\text {SmaI }}$-MRSA isolates are found in areas with the highest pig density. This could be explained by the frequent movement of pigs between farms in the Netherlands. This facilitates the dissemination of ST398 MRSA on a national scale. A similar situation took place during the foot- and -mouth epidemic in England of 2001 [33].

To provide additional resolution on the molecular evolution and dissemination of MRSA lineages, several typing techniques such as PFGE, SCCmec-and spa-typing have been developed. Since PFGE with SmaI does not digest the DNA of ST398 isolates, spa-typing has been the method of choice for characterizing $\mathrm{NT}_{S m a \mathrm{I}}$-MRSA isolates. However, given the low diversity in spa-types it is hard to ascertain health care-associated transmission if two or more different spa-types are present in the same institution. Fanoy et al. described an outbreak in a residential care facility where two spa-types (t2383 and t011) were prevalent [18]. After re-examination of the same isolates the PFGE profiles using Cfr9I were indistinguishable, indicating isogenicity. Moreover, the discriminatory ability of spa-typing of $\mathrm{NT}_{S m a \mathrm{I}}$-MRSA is compromised by the fact that more than $80 \%$ of the $\mathrm{NT}_{S m a \mathrm{I}}-\mathrm{MRSA}$ in 
Table 1 Overview of transmission of ST398 MRSA on 9 farms $(n=40)$

\begin{tabular}{|c|c|c|c|c|c|}
\hline Strain $\mathrm{nr}$ & Farm & $\begin{array}{l}\text { spa- } \\
\text { type }\end{array}$ & Origin & $\begin{array}{c}\text { PFGE } \\
\text { pattern }\end{array}$ & Coefficient $^{*}$ \\
\hline 1110701181 & 1 & t011 & farmer & B3 & 70 \\
\hline 1110700844 & 1 & t011 & pig & D7 & \\
\hline 1110701184 & 2 & t011 & farmer & D4 & 86 \\
\hline 1110700857 & 2 & t011 & pig & D4 & \\
\hline 1110701182 & 2 & t011 & employee & E1 & \\
\hline 1110701185 & 2 & t011 & relative & E1 & \\
\hline 1110701429 & 3 & t011 & pig & B1 & 87 \\
\hline 1110701595 & 3 & t011 & relative & B2 & \\
\hline 1110701592 & 3 & t011 & farmer & D19 & \\
\hline 1110701192 & 4 & $\mathrm{t} 108$ & farmer & D1 & 100 \\
\hline 1110700908 & 4 & $\mathrm{t} 108$ & pig & D1 & \\
\hline 1110701196 & 5 & t567 & farmer & D18 & 52 \\
\hline 1110701197 & 5 & $\mathrm{t} 567$ & relative & D18 & \\
\hline 1110700912 & 5 & t567 & pig & 1 & \\
\hline 1110701611 & 6 & t108 & dust & D1 & 84 \\
\hline 1110701614 & 6 & $\mathrm{t} 108$ & dust & D1 & \\
\hline 1110701604 & 6 & $\mathrm{t} 108$ & pig & D1 & \\
\hline 1110701200 & 6 & t011 & farmer & D20 & \\
\hline 1110701612 & 6 & t011 & dust & D4 & \\
\hline 1110701605 & 6 & t011 & pig & D4 & \\
\hline 1110701201 & 6 & t011 & relative & E1 & \\
\hline 1110701600 & 7 & $\mathrm{t} 2741$ & employee & D14 & 95 \\
\hline 1110701596 & 7 & t011 & farmer & D14 & \\
\hline 1110701580 & 7 & t011 & pig & D14 & \\
\hline 1110701601 & 7 & $\mathrm{t} 108$ & employee & D21 & \\
\hline 1110701576 & 7 & t011 & pig & D21 & \\
\hline 1110701577 & 7 & t011 & pig & D21 & \\
\hline 1110700882 & 8 & t011 & pig & $\mathrm{B} 1$ & 66 \\
\hline 1110700884 & 8 & $\mathrm{t} 108$ & pig & D1 & \\
\hline 1110700876 & 8 & $\mathrm{t} 108$ & pig & D3 & \\
\hline 1110700889 & 8 & $\mathrm{t} 2330$ & dust & D4 & \\
\hline 1110701188 & 8 & $\mathrm{t} 2330$ & relative & D4 & \\
\hline 1110701191 & 8 & $\mathrm{t} 2330$ & relative & D4 & \\
\hline 1110700890 & 8 & $\mathrm{t} 108$ & dust & K & \\
\hline 1110701791 & 9 & t108 & dust & D1 & 86 \\
\hline 1110701783 & 9 & $\mathrm{t} 108$ & pig & D1 & \\
\hline 1110701788 & 9 & $\mathrm{t} 108$ & pig & D1 & \\
\hline 1110703030 & 9 & $\mathrm{t} 108$ & relative & D1 & \\
\hline 1110703031 & 9 & t588 & relative & D1 & \\
\hline 1110703032 & 9 & t108 & relative & D3 & \\
\hline
\end{tabular}

* Dice similarity coefficient, using UPGMA. Optimization $0,5 \%$, position tolerance

the Netherlands belong either to spa-type t011 or t108 [23]. With the modified Cfr9I PFGE a better tool for epidemiological investigation has become available.

The results obtained by Cfr 9 I PFGE of isolates from veterinarians and their close family members showed possible transmission of ST398. Five out of eight pairs had identical profiles. The family members had themselves no contact with animals and were presumably infected by the occupationally exposed veterinarian. Two pairs of PFGE patterns among family members were not identical. Their isolates also had different spa-types. Family members may have been colonized by one MRSA through the veterinarian and subsequently the veterinarian may have been re-colonized by another MRSA after occupational exposure. One pair differed only in a single PFGE band probably as a consequence of micro-evolution.

A study on nine different farms revealed that the PFGE patterns of isolates from seven farms were related, but PFGE patterns varied within and between the farms. For example, farm 7 , yielded only 2 very closely related PFGE patterns (D14, D21; similarity 95\%), while other farms, like farm 8 , showed 5 different PFGE patterns (B1, D1, D3, D4 and K) and had a similarity of only $66 \%$. Different batches of animals entering the farm, carrying different $\mathrm{NT}_{\text {SmaI }}$-MRSA, could have caused variation within farms. Further study is needed to confirm that farms with a fast turnover of pigs indeed show a higher diversity of PFGE patterns of $\mathrm{NT}_{S m a \mathrm{I}}$-MRSA.

\section{Conclusions}

In conclusion, the modified PFGE protocol for $C f r 9 \mathrm{I}$ provided highly informative banding patterns and showed good reproducibility. The PFGE results showed diversity within and between the two most prevalent spa-types among $\mathrm{NT}_{S m a \mathrm{I}}-\mathrm{MRSA}$. PFGE confirmed transmission of the ST398 clonal lineage within families and in a residential care facility. The modified PFGE approach can be used as a method for selecting important and distinct ST398 isolates for further research. The adjustments in the PFGE protocol using Cfr9I are easy to implement in laboratories which already have a PFGE facility, creating a powerful tool to study the ST398 clonal lineage.

\section{Author details \\ ${ }^{1}$ Centre for infectious disease control, National institute for public health and the environment (RIVM), Bilthoven, the Netherlands. ${ }^{2}$ Department of medical microbiology and infection control, VU medical centre, Amsterdam, the Netherlands. ${ }^{3}$ Laboratory for microbiology and infection control, Amphia hospital, Breda, the Netherlands.}

\section{Authors' contributions}

TB carried out all molecular typing and drafted the manuscript. AJN participated in the design of the study and revised the manuscript critically for important intellectual content. LMS has made substantial contributions to conception and design of the study. KWZ was responsible for analysis and interpretation of the data and revised the manuscript critically. JAJWK has been involved in drafting the manuscript and revising it critically for important intellectual content. HG participated in the design of the study and has given final approval of the version to be published. XWH participated in the design of the study, has been involved in drafting the manuscript and revising it critically for important intellectual content. All authors read and approved the final manuscript. 
Received: 15 May 2009

Accepted: 9 February 2010 Published: 9 February 2010

\section{References}

1. Vandenesch F, Naimi T, Enright MC, Lina G, Nimmo GR, Heffernan $H$, Liassine N, Bes M, Greenland T, Reverdy ME, Etienne J: Communityacquired methicillin-resistant Staphylococcus aureus carrying PantonValentine leukocidin genes: worldwide emergence. Emerg Infect Dis 2003, 9:978-984

2. Zetola N, Francis JS, Nuermberger EL, Bishai WR: Community-acquired methicillin-resistant Staphylococcus aureus: an emerging threat. Lancet Infect Dis 2005, 5:275-286.

3. de Neeling AJ, Broek van den MJ, Spalburg EC, van Santen-Verheuvel MG, Dam-Deisz WD, Boshuizen HC, Giessen van de AW, van Duijkeren E, Huijsdens XW: High prevalence of methicillin resistant Staphylococcus aureus in pigs. Vet Microbiol 2007, 122:366-372.

4. Huijsdens XW, van Dijke BJ, Spalburg E, van Santen-Verheuvel MG, Heck ME, Pluister GN, Voss A, Wannet WJ, de Neeling AJ: Community-acquired MRSA and pig-farming. Ann Clin Microbiol Antimicrob 2006, 5:26.

5. Broek van den IV, van Cleef BA, Haenen A, Broens EM, Wolf van der PJ, Broek van den MJ, Huijsdens XW, Kluytmans JA, Giessen van der AW, Tiemersma EW: Methicillin-resistant Staphylococcus aureus in people living and working in pig farms. Epidemiol Infect 2008, 1-9.

6. Khanna T, Friendship R, Dewey C, Weese JS: Methicillin resistant Staphylococcus aureus colonization in pigs and pig farmers. Vet Microbiol 2008, 128:298-303.

7. Voss A, Loeffen F, Bakker J, Klaassen C, Wulf M: Methicillin-resistant Staphylococcus aureus in pig farming. Emerg Infect Dis 2005, 11:1965-1966.

8. Cuny C, Strommenger B, Witte W, Stanek C: Clusters of infections in horses with MRSA ST1, ST254, and ST398 in a veterinary hospital. Microb Drug Resist 2008, 14:307-310.

9. Witte W, Strommenger B, Stanek C, Cuny C: Methicillin-resistant Staphylococcus aureus ST398 in humans and animals, Central Europe. Emerg Infect Dis 2007, 13:255-258.

10. Persoons D, Van Hoorebeke $S$, Hermans K, Butaye $P$, de Kruif A, Haesebrouck F, Dewulf J: Methicillin-resistant Staphylococcus aureus in poultry. Emerg Infect Dis 2009, 15:452-453.

11. Mooij TA, Jenkins J, Thijssen S: MRSA in calves. Infectieziekten Bulletin 2007, 18:234-236.

12. Armand-Lefevre L, Ruimy $R$, Andremont A: Clonal comparison of Staphylococcus aureus isolates from healthy pig farmers, human controls, and pigs. Emerg Infect Dis 2005, 11:711-714.

13. Guardabassi L, Stegger M, Skov R: Retrospective detection of methicillin resistant and susceptible Staphylococcus aureus ST398 in Danish slaughter pigs. Vet Microbiol 2007, 122:384-386.

14. Meemken D, Cuny C, Witte W, Eichler U, Staudt R, Blaha T: Occurrence of MRSA in pigs and in humans involved in pig production-preliminary results of a study in the northwest of Germany. Dtsch Tierarztl Wochenschr 2008, 115:132-139.

15. Smith TC, Male MJ, Harper AL, Kroeger JS, Tinkler GP, Moritz ED, Capuano AW, Herwaldt LA, Diekema DJ: Methicillin-resistant Staphylococcus aureus (MRSA) strain ST398 is present in midwestern U.S. swine and swine workers. PLOS ONE 2008, 4:e4258.

16. Ekkelenkamp MB, Sekkat M, Carpaij N, Troelstra A, Bonten MJ: Endocarditis due to methicillin-resistant Staphylococcus aureus originating from pigs. Ned Tijdschr Geneeskd 2006, 150:2442-2447.

17. Yu F, Chen Z, Liu C, Zhang X, Lin X, Chi S, Zhou T, Chen Z, Chen X: Prevalence of Staphylococcus aureus carrying Panton-Valentine leukocidin genes among isolates from hospitalised patients in China. Clin Microbiol Infect 2008, 14:381-384.

18. Fanoy E, Helmhout LC, Vaart van der WL, Weijdema K, van SantenVerheuvel MG, Thijsen SF, de Neeling AJ, van Wamel WJ, Manaskova SH, Kingma-Thijssen JL: An outbreak of non-typeable MRSA within a residential care facility. Euro Surveill 2009, 14(1):19080, pii.

19. Kaufmann ME: Pulsed-field gel electrophoresis. Totowa N.J.: Humana press 1998.

20. Bens CC, Voss A, Klaassen CH: Presence of a novel DNA methylation enzyme in methicillin-resistant Staphylococcus aureus isolates associated with pig farming leads to uninterpretable results in standard pulsedfield gel electrophoresis analysis. J Clin Microbiol 2006, 44:1875-1876.
21. Frenay HM, Bunschoten AE, Schouls LM, van Leeuwen WJ, VandenbrouckeGrauls CM, Verhoef J, Mooi FR: Molecular typing of methicillin-resistant Staphylococcus aureus on the basis of protein A gene polymorphism. Eur J Clin Microbiol Infect Dis 1996, 15:60-64.

22. Harmsen D, Claus H, Witte W, Rothganger J, Claus H, Turnwald D, Vogel U: Typing of methicillin-resistant Staphylococcus aureus in a university hospital setting by using novel software for spa repeat determination and database management. J Clin Microbiol 2003, 41:5442-5448.

23. Huijsdens XW, Bosch T, van Santen-Verheuvel MG, Spalburg E, Pluister GN, van Luit M, Heck MEOC, Haenen A, de Neeling AJ: Molecular characterization of PFGE non-typeable methicillin-resistant Staphylococcus aureus in the Netherlands, 2007. Eurosurveillance 2009, 14(38).

24. Schouls LM, Spalburg EC, van Luit M, Huijsdens XW, Pluister GN, van Santen-Verheuvel MG, Heide van der HG, Grundmann H, Heck ME, de Neeling AJ: Multiple-locus variable number tandem repeat analysis of Staphylococcus aureus: comparison with pulsed-field gel electrophoresis and spa-typing. PLOS ONE 2009, 4:e5082.

25. Bhat M, Dumortier C, Taylor BS, Miller M, Vasquez G, Yunen J, Brudney K, Sanchez EJ, Rodriguez-Taveras C, Rojas R: Staphylococcus aureus ST398, New York City and Dominican Republic. Emerg Infect Dis 2009, 15:285-287.

26. Murchan S, Kaufmann ME, Deplano A, de Ryck R, Struelens M, Zinn CE, Fussing V, Salmenlinna S, Vuopio-Varkila J, El Solh N: Harmonization of pulsed-field gel electrophoresis protocols for epidemiological typing of strains of methicillin-resistant Staphylococcus aureus: a single approach developed by consensus in 10 European laboratories and its application for tracing the spread of related strains. J Clin Microbiol 2003, 41:1574-1585.

27. Boye K, Bartels MD, Andersen IS, Moller JA, Westh $\mathrm{H}$ : A new multiplex PCR for easy screening of methicillin-resistant Staphylococcus aureus SCCmec types I-V. Clin Microbiol Infect 2007, 13:725-727.

28. McDougal LK, Steward CD, Killgore GE, Chaitram JM, MCAllister SK, Tenover FC: Pulsed-field gel electrophoresis typing of oxacillin-resistant Staphylococcus aureus isolates from the United States: establishing a national database. J Clin Microbiol 2003, 41:5113-5120.

29. Siksnys $V$, Pleckaityte M: Catalytic and binding properties of restriction endonuclease Cfr9l. Eur J Biochem 1993, 217:411-419.

30. van Belkum A, Melles DC, Peeters JK, van Leeuwen WB, van Duijkeren E, Huijsdens XW, Spalburg E, de Neeling AJ, Verbrugh HA, Dutch Working Party on Surveillance and Research of M-S: Methicillin-resistant and -susceptible Staphylococcus aureus sequence type 398 in pigs and humans. Emerg Infect Dis 2008, 14:479-483.

31. Struelens MJ, Deplano A, Godard C, Maes N, Serruys E: Epidemiologic typing and delineation of genetic relatedness of methicillin-resistant Staphylococcus aureus by macrorestriction analysis of genomic DNA by using pulsed-field gel electrophoresis. J Clin Microbiol 1992, 30:2599-2605.

32. Tenover FC, Arbeit RD, Goering RV, Mickelsen PA, Murray BE, Persing DH, Swaminathan B: Interpreting chromosomal DNA restriction patterns produced by pulsed-field gel electrophoresis: criteria for bacterial strain typing. J Clin Microbiol 1995, 33:2233-2239.

33. Alexandersen S, Zhang Z, Donaldson Al, Garland AJ: The pathogenesis and diagnosis of foot-and-mouth disease. J CompPathol 2003, 129:1-36.

doi:10.1186/1471-2180-10-40

Cite this article as: Bosch et al.: PFGE diversity within the methicillinresistant Staphylococcus aureus clonal lineage ST398. BMC Microbiology 2010 10:40. 